\title{
Exposure to carbon dioxide-rich seawater is stressful for some deep-sea species: an in situ, behavioral study
}

\author{
D. Thistle ${ }^{1, *}$, L. Sedlacek ${ }^{1}$, K. R. Carman ${ }^{2}$, J. W. Fleeger ${ }^{2}$, P. G. Brewer ${ }^{3}$, J. P. Barry ${ }^{3}$ \\ ${ }^{1}$ Department of Oceanography, Florida State University, Tallahassee, Florida 32306-4320, USA \\ ${ }^{2}$ Department of Biological Sciences, Louisiana State University, Baton Rouge, Louisiana 70803-1725, USA \\ ${ }^{3}$ Monterey Bay Aquarium Research Institute, Sandholdt Road, Moss Landing, California 95039-9644, USA
}

\begin{abstract}
Since the beginning of the industrial revolution, the concentration of the greenhouse gas carbon dioxide in the atmosphere has increased from 275 to $370 \mathrm{ppm}_{i}$ the increase is thought to have caused much of the rise in global temperature that has occurred during the same period. A means of mitigating its effects is to collect industrial carbon dioxide and sequester it in the deep ocean. Knowledge of effects of such sequestration on deep-sea organisms is crucial to evaluation of the wisdom of deep-ocean sequestration. We therefore tested deep-sea animals for indications that exposure to carbon dioxide-rich seawater is stressful. Our study site was at $3087 \mathrm{~m}$ depth off the coast of central California $\left(36^{\circ} 41.91^{\prime} \mathrm{N}, 123^{\circ} 0.14^{\prime} \mathrm{W}\right)$. We deployed liquid carbon dioxide in open-topped containers on the sea floor. The carbon dioxide reacted with the carbonate system in the overlying seawater, and carbon dioxide-rich seawater flowed out onto the sediment. We placed invertedfunnel traps near the containers and $\sim 75 \mathrm{~m}$ away from them. Measurements of $\mathrm{pH}$ confirmed that the area near the containers was exposed to carbon dioxide-rich seawater. As a test taxon, we chose harpacticoid copepods. The traps near the source of the carbon dioxide-rich seawater caught significantly more harpacticoids than those far from it. The harpacticoids apparently attempted to escape from the advancing front of carbon dioxide-rich seawater and therefore presumably found exposure to it to be stressful.
\end{abstract}

KEY WORDS: Global warming $\cdot \mathrm{CO}_{2}$ sequestration $\cdot$ Deep sea $\cdot$ Benthic infauna $\cdot$ Harpacticoid copepods $\cdot$ Emergence

Resale or republication not permitted without written consent of the publisher

\section{INTRODUCTION}

Since the onset of the industrial revolution, the carbon dioxide concentration in the atmosphere has increased from 275 to 370 ppm (Takeuchi et al. 1997, Hoffert et al. 2002). Because carbon dioxide is a greenhouse gas, its increasing concentration is thought to be a major cause of the increase in average global temperature during this period (Hegerl \& Bindoff 2005). Global warming will cause changes with large effects on the terrestrial environment. For example, river runoff will increase (Gedney et al. 2006), and the melting of ice presently on land will cause sea level to rise by meters, inundating low-lying areas inhabited by large human populations. Governmental and nongovernmental bodies are therefore interested in limiting the amount of carbon dioxide that enters the atmosphere. In one plan, carbon dioxide would be collected from point sources, such as power plants, and injected into the deep sea (Marchetti 1977). The environmental costs of creating carbon dioxide-rich seawater in the deep sea are not yet known, but laboratory experiments on shallow-water species have shown that increasing carbon dioxide concentrations can affect animal physiology negatively and can cause death (Pörtner et al. 2004). Deep-sea animals are 
thought to be particularly susceptible to environmental perturbations because they ordinarily experience much less environmental variability than do shallowwater animals (Shirayama 1995, 1997, Seibel \& Walsh 2001, 2003), but experimental studies have just begun (Tamburri et al. 2000, Barry et al. 2003, 2004, 2005, Carman et al. 2004, Thistle et al. 2005, 2006, Fleeger et al. 2006), and little in situ evidence is available.

The literature on ocean sequestration includes proposals to dispense liquid carbon dioxide near, on, and in the deep-sea floor. The first 2 methods would produce carbon dioxide-rich seawater that would spread over the sediment. To investigate the consequences, we used the remotely operated vehicle 'Tiburon' of the Monterey Bay Aquarium Research Institute and the system described in Brewer et al. (1999) to create carbon dioxide-rich seawater on the seafloor.

We focused on harpacticoid copepods, a group of meiofaunal crustaceans that is abundant and diverse in the deep sea (Thistle 1978, Seifried 2004). Behavioral information on deep-sea harpacticoids is limited, but some shallow-water harpacticoid species are epibenthic (Noodt 1971, Hicks \& Coull 1983), making forays from the sediment surface into the near-bottom water. Others are more intimately associated with the seabed but occasionally emerge from it and enter the water column (Bell et al. 1984, Armonies 1988, Thistle 2003). One proposed explanation for their entrance into the near-bottom water is that they do so to escape deteriorating conditions (Thistle 2003).

Some deep-sea harpacticoid species may also use the near-bottom water. In samples from sediment traps set to collect $4 \mathrm{~m}$ above bottom at $2347 \mathrm{~m}$ depth, L. Guidi-Guilvard (pers. comm.) found harpacticoids whose morphologies suggested that they were epibenthic or benthic. We therefore asked whether deep-sea harpacticoids exposed to carbon dioxide-rich seawater would enter the near-bottom water in unusual numbers, indicating that they found the carbon dioxiderich seawater stressful as has been shown to be the case for other deep-sea animals (Tamburri et al. 2000, Barry et al. 2003, Vetter \& Smith 2005).

J. P. Barry has been investigating the environmental consequences of deep-ocean sequestration in a series of in situ experiments (see Barry et al. 2005). Our work derives from his CO2-6 field program. CO2-6 is similar to CO2-5, which is described in Barry et al. (2005).

\section{MATERIALS AND METHODS}

Study site. The study site was at $3087 \mathrm{~m}$ depth on the continental rise off the coast of central California ( $36^{\circ} 41.91^{\prime} \mathrm{N}, 123^{\circ} 0.14^{\prime} \mathrm{W}$, Fig. 1). The sediment was silt and clay, and the seafloor was macroscopically flat in the

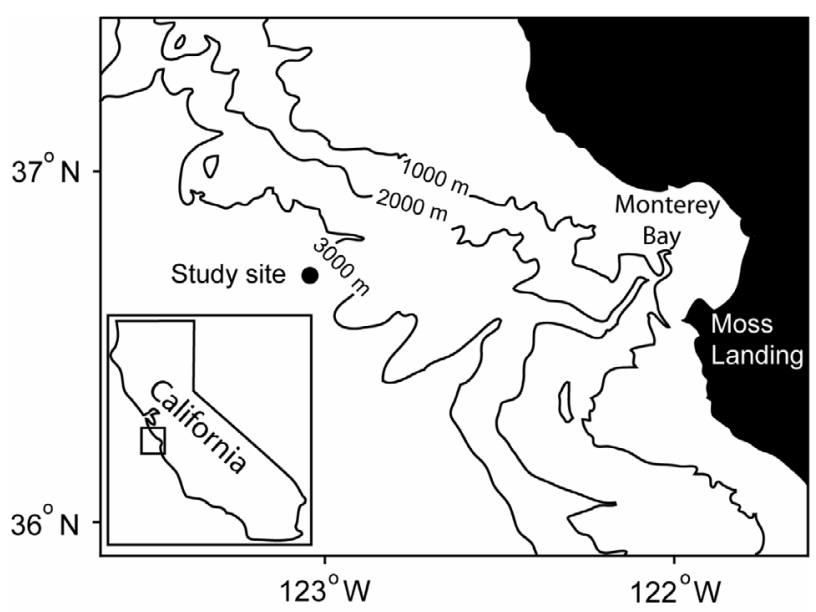

Fig. 1. Eastern Pacific off central California showing location of the study site

approximately $200 \times 200 \mathrm{~m}$ area we explored. The salinity, temperature, and oxygen concentration of the nearbottom water during our visits (December 2004 and January 2005) were $34.6,1.58^{\circ} \mathrm{C}$, and $115.6 \mu \mathrm{M}$, respectively, determined from sensors mounted on the 'Tiburon'. An in situ $\mathrm{pH}$ of 7.78 (seawater scale) was calculated from total carbon $\left(2352.7 \mu \mathrm{mol} \mathrm{kg}{ }^{-1}\right)$ and alkalinity (2442.3 $\mu \mathrm{mol} \mathrm{kg}^{-1}$ ) data interpolated for $3087 \mathrm{~m}$ from World Ocean Circulation Experiment (woce.nodc. noaa.gov) Stn P17-10.

Experimental layout. Although carbon dioxide is liquid and denser than seawater at the temperature and pressure of our study site, near-bottom flow would disperse it rapidly if it were unconfined. We therefore placed $15 \mathrm{~cm}$-tall sections of $48 \mathrm{~cm}$-diameter, polyvinyl chloride (PVC) pipe on their sides in the seafloor such that $\sim 13 \mathrm{~cm}$ extended out of the sediment; 15 such open-topped containers were arranged in a circle $\sim 14 \mathrm{~m}$ in diameter (Fig. 2). The 'Tiburon' filled each container with $\sim 121$ of liquid carbon dioxide, which reacted with the carbonate system in the overlying seawater to form a carbon dioxide-rich dissolution plume that flowed out over the seabed. During filling, a small amount $(<1 \%$ of the volume) wafted out of the container as drops that fell to the surrounding seabed. We also selected a control area $\sim 75 \mathrm{~m}$ from the ring of carbon dioxide-filled containers.

Detection of carbon dioxide-rich seawater. Because carbon dioxide is difficult to measure, we measured $\mathrm{pH}$, as is commonly done (see for example Tamburri et al. 2000, Barry et al. 2003, 2004). To detect carbon dioxiderich seawater emanating from the group of containers, we placed a recording $\mathrm{pH}$ sensor that measured at 3 to $5 \mathrm{~cm}$ above the seabed (SeaBird Model 19-Plus CTD equipped with a SeaBird pH sensor) at the center, side, and margin of the ring of containers (Fig. 2). An additional unit was placed in the control area $\sim 75 \mathrm{~m}$ away. 


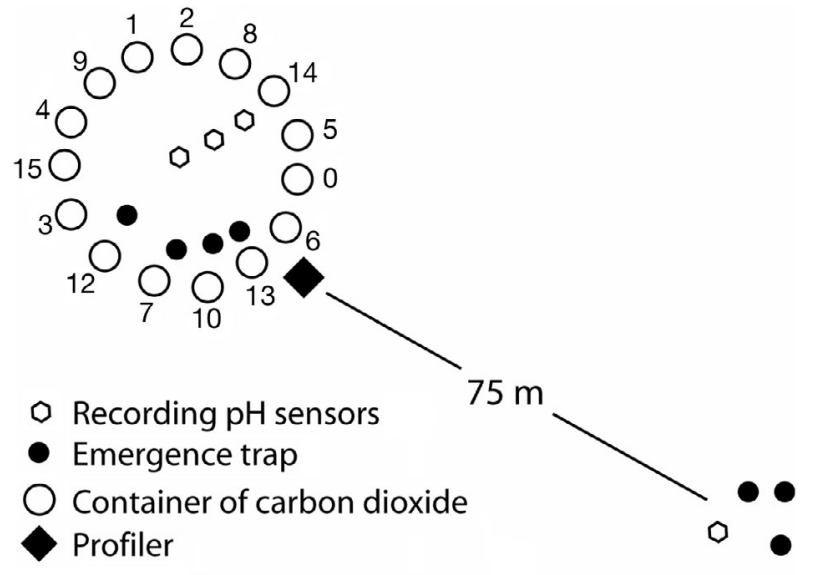

Fig. 2. Diagram (not to scale) of study site showing arrangement of arbitrarily numbered containers of carbon dioxide, recording $\mathrm{pH}$ sensors, profiler, and the 2 groups of emergence traps

We measured the $\mathrm{pH}$ of the lower $1.7 \mathrm{~cm}$ of the nearbottom water and the upper $4.3 \mathrm{~cm}$ of the sediment in situ using a modified Unisense ${ }^{\circledR}$ automated, deepsea, microprofiling system ('profiler'). A computercontrolled, precision profiler carried a $\mathrm{pH}$ sensor and the electronics necessary to measure and record its signals. An external switch allowed us to initiate profiling in situ. A 24 V DeepSea Power \& Light SeaBattery powered the system. Profiler, battery, switch, and syntactic-foam flotation were mounted on a tripod frame $\sim 1 \mathrm{~m}$ on each side. The sensors were Unisense ${ }^{\circledR} \mathrm{pH}$ microelectrodes (100 $\mu \mathrm{m}$ diameter tip, built-in reference electrode) that we calibrated at in situ temperature with commercial buffers (pH 5 and 9) before and after deployment. The profiler was delivered to the seabed by a free-vehicle 'elevator' consisting of a platform, flotation, and a sonar beacon.

On 13 December 2004, we filled Containers 0, 5, 6, and 13 with 121 each of carbon dioxide and partially filled (2.5 1) Container 10. On 14 December 2004, we finished filling Container 10; filled Containers 3, 7, and 12 ; and moved the profiler to a position $\sim 2 \mathrm{~m}$ outside the ring of containers (Fig. 2). The profiler measured 2 profiles and then failed. During data analysis, we took the height of the abrupt decrease in $\mathrm{pH}$ as the position of the sediment surface and aligned the profiles accordingly.

We measured $\mathrm{pH}$ profiles in 4 cores from the control area on 14 December 2004, before additional carbon dioxide was delivered to the treatment area on that day. On 15 December 2004, we filled the remaining containers. At the end of the experiment, we measured $\mathrm{pH}$ profiles in 9 cores from both the treatment and control areas. In each case, the cores were transferred within a few minutes of reaching the surface to a $4^{\circ} \mathrm{C}$ cold room. For profiling, we submerged each core in a bath of chilled water to the level of the sediment surface. We used an externally calibrated, Unisense ${ }^{\circledR} \mathrm{pH}$ microelectrode $(100 \mu \mathrm{m}$ tip diameter, built-in reference electrode) connected to a Knick ${ }^{\circledR}$ Portamess $913 \mathrm{pH}$ meter. Using a micromanipulator, we measured the $\mathrm{pH}$ (generally at $250 \mu \mathrm{m}$ depth intervals) from $\sim 2 \mathrm{~mm}$ above the sediment surface to $\sim 8 \mathrm{~mm}$ into the sediment. We measured at larger intervals for an additional $10 \mathrm{~mm}$. During data analysis, we adjusted the vertical position of the profiles, as for the in situprofiler data.

Trap design. As is routine in emergence studies (see Hicks 1986, Thistle 2003), our trap was based on an inverted funnel (Fig. 3). The collecting chamber was a $14.6 \mathrm{~cm}$ tall PVC pipe, to which a removable PVC lid and a custom-made PVC funnel with openings of 22 and $1.8 \mathrm{~cm}$ diameter were fitted. The lid contained a $1.9 \mathrm{~cm}$-diameter vent covered with $30 \mu \mathrm{m}$-aperture mesh and a $1.9 \mathrm{~cm}$-diameter port closed by a nylon screw. The collecting chamber was held $4 \mathrm{~cm}$ above the seabed by 4 legs equipped with horizontal flanges that minimized the tendency of the trap to settle into the seabed. The nominal distance from the seabed to the top of the funnel spout was $9.6 \mathrm{~cm}$.

Before deployment, each trap was placed in a carrier that contained a pedestal tipped with a rubber stopper that sealed the collecting chamber. We filled each collecting chamber with salinity 35 artificial seawater. To each, we added 50 freeze-killed, adult specimens of

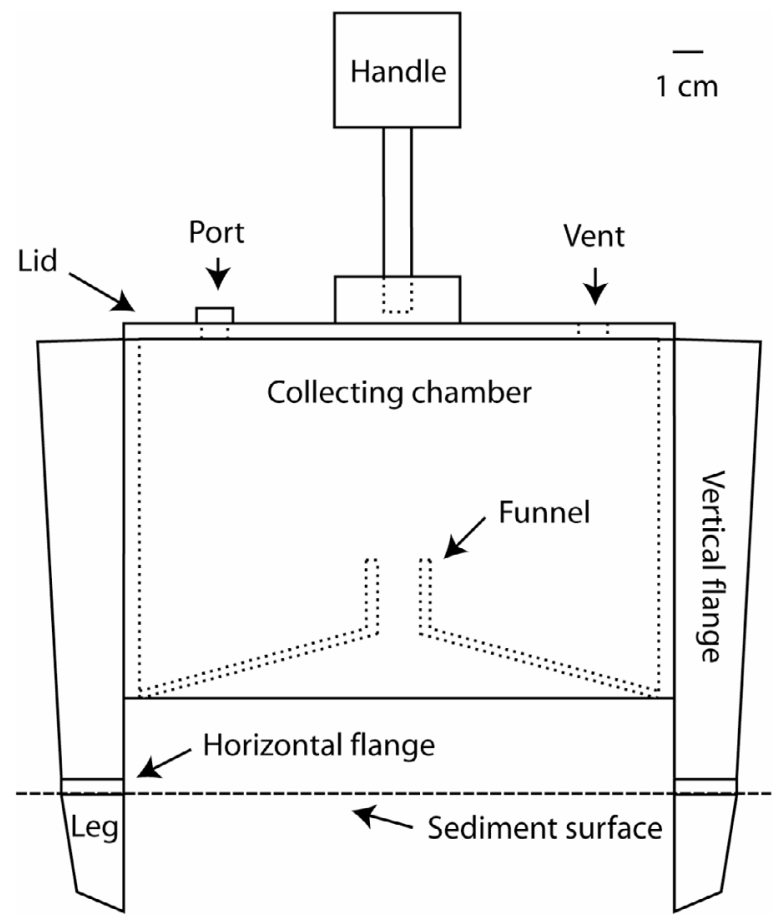

Fig. 3. Emergence trap and its components 
the shallow-water harpacticoid Schizopera knabeni Lang obtained from a laboratory culture. These allowed us to check the possibility that more harpacticoids decayed to unrecognizability in traps placed in the treatment area than in those in the control area or vice versa.

The traps in their carriers were transported to the seabed by the free-vehicle elevator. While each trap was moved from the carrier to its intended location, it rested on a rubber-stopper-tipped pedestal on the 'Tiburon'. On 14 December 2004, 4 traps were placed inside the circle; adjacent traps were separated by $\sim 1 \mathrm{~m}$. Three traps were placed with the same intertrap spacing in the control area (Fig. 2).

To recover the traps, we reversed the process $37 \mathrm{~d}$ after deployment. On deck, the contents of each trap were washed on a sieve of $30 \mu \mathrm{m}$-aperture mesh. The material retained by the sieve was preserved in a solution $(1: 9, \mathrm{v}: \mathrm{v})$ of formalin and artificial seawater of salinity 35 that was buffered with sodium borate.

Species-composition comparison. To determine whether the fauna caught in the traps exposed to carbon dioxide-rich seawater differed in species composition from that caught in the traps from the control area, we first converted the species' abundances in each trap to percentages of the total abundance in the trap to eliminate effects of abundance on the comparison (Clarke \& Gorley 2001). We then square-root-transformed the data and calculated a Bray-Curtis coefficient of similarity (Bray \& Curtis 1957) between each pair of samples. To determine whether the withingroup similarities were significantly greater than the between-group similarities, we used the randomization-based ANOSIM procedure in Version 5 of the Primer software package (Clarke \& Gorley 2001).

\section{RESULTS}

\section{Detection of carbon dioxide-rich seawater}

$$
\text { Recording } \mathrm{pH} \text { meters }
$$

The 3 instruments in the ring of containers measured similar variations in $\mathrm{pH}$ at 3 to $5 \mathrm{~cm}$ above the seabed during the experiment (Fig. 4). The average $\mathrm{pH}$ reduction was only $0.01 \mathrm{pH}$ units, but perturbations as large as $-0.31 \mathrm{pH}$ units occurred occasionally. The $\mathrm{pH}$ sensor in the control area failed.

\section{In situ profiler}

On 14 December 2004, after 108 l of liquid carbon dioxide had been pumped into containers, the $\mathrm{pH}$ profiler measured 2 profiles: the first began at 18:23 $\mathrm{h}$ and the second at 21:36 h Pacific Standard Time. Measurements were made at $0.25 \mathrm{~mm}$ intervals for $60 \mathrm{~mm}$ beginning in the near-bottom water and penetrating the seabed (Fig. 5). On recovery, we discovered that the sensor had drifted out of calibration, as is often the case (Barry et al. 2005). We followed Barry et al.'s (2005) procedure and rescaled our profiles such that the measurements in what appeared to be ambient seawater (see below) were given the value of the $\mathrm{pH}$ of the near-bottom seawater of the region and depth ( $\mathrm{pH} 7.78$, seawater scale); other measurements were adjusted accordingly.

The $\mathrm{pH}$ measurements in the first $\sim 17 \mathrm{~mm}$ of the profiles were essentially the same, indicating that the sensor was in the overlying seawater. Below the $17 \mathrm{~mm}$ mark, the $\mathrm{pH}$ decreased markedly in both profiles. We

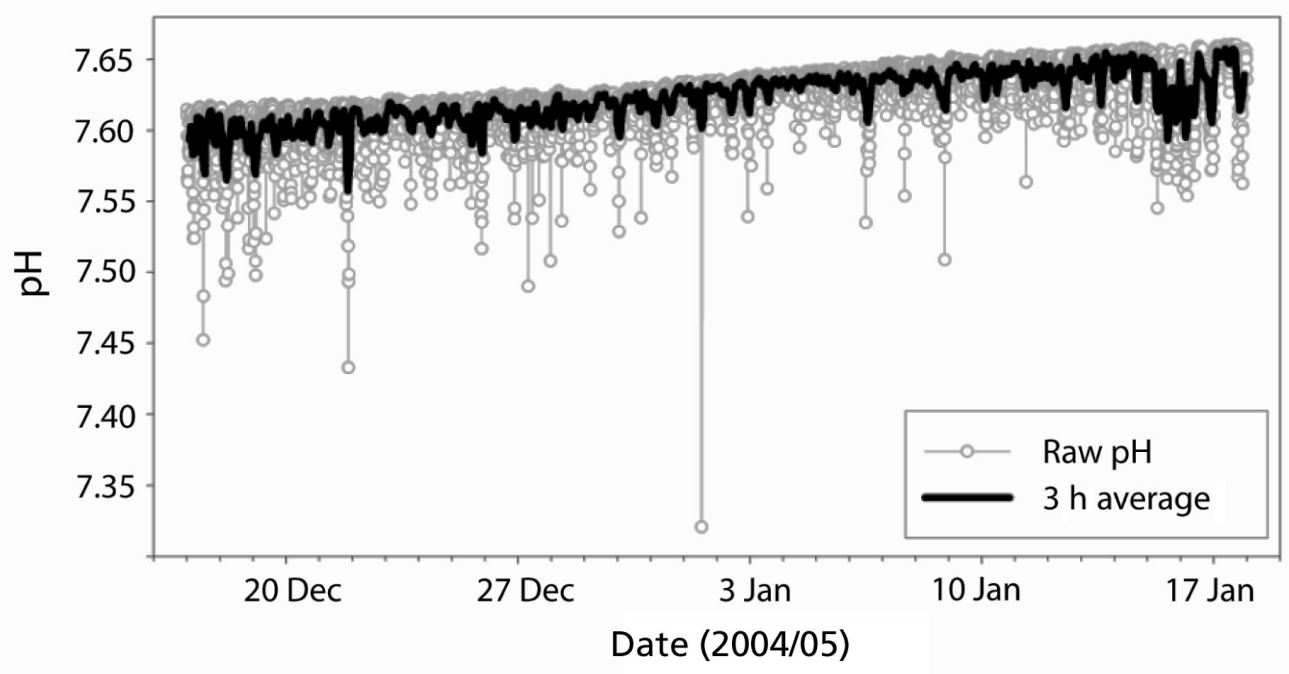

Fig. 4. Data from recording $\mathrm{pH}$ sensor nearest to center of the circle of containers, showing acidic excursions. Data are from $5 \mathrm{~cm}$ above bottom and have not been corrected for sensor drift 


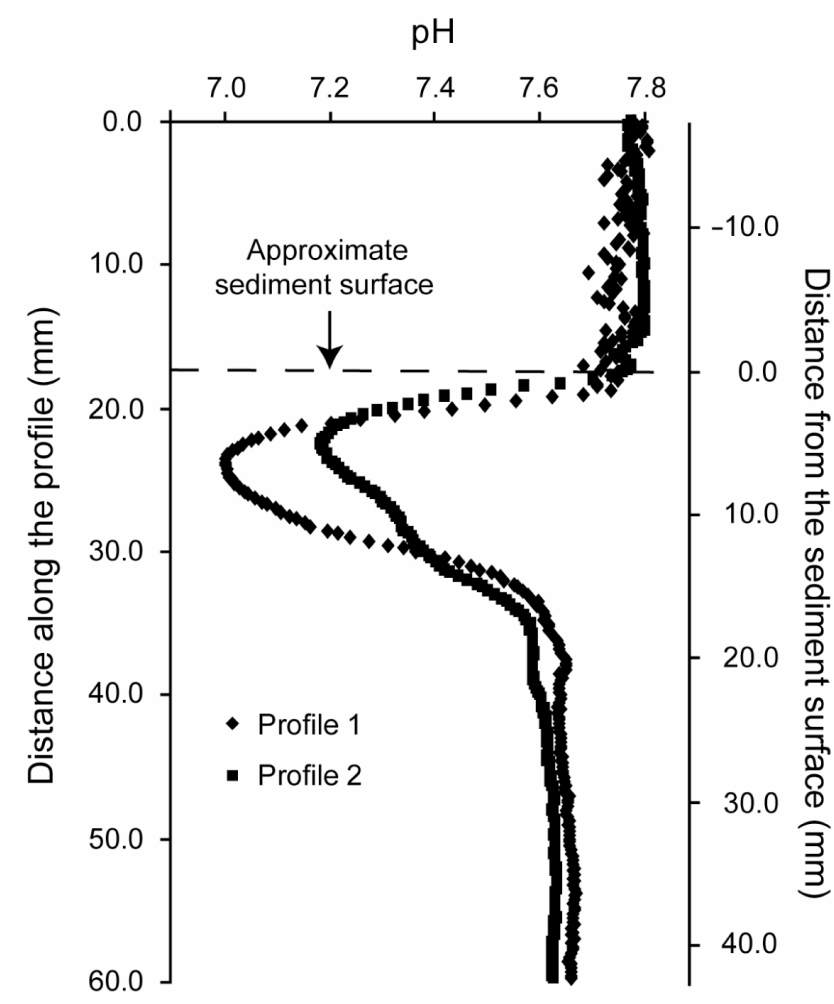

Fig. 5. In situ $\mathrm{pH}$ profiles $\sim 2 \mathrm{~m}$ outside the ring of carbon dioxide-filled containers after 9 had been filled, showing presence of unusually acidic seawater in top $\sim 18 \mathrm{~mm}$ of sediment. The $\mathrm{pH}$ measured by profiler in near-bottom water was adjusted to 7.78 , the literature value for the area and depth, and the other measurements were adjusted accordingly

took the inflection point to be the location of the sediment surface. The $\mathrm{pH}$ reached a minimum at the $\sim 24 \mathrm{~mm}$ mark ( $\sim 7 \mathrm{~mm}$ below the sediment surface) in Profile 1 and at the $\sim 22 \mathrm{~mm}$ mark ( $\sim \mathrm{mm}$ below the sediment surface) in Profile 2. Below approximately the $35 \mathrm{~mm}$ mark ( 18 $\mathrm{mm}$ below the sediment surface), the $\mathrm{pH}$ became similar and essentially constant in both profiles.

\section{pH measurements on cores}

The pH profiles (Fig. 6) for the 4 cores from the control area at the start of the experiment had the expected shape in the upper $\sim 16 \mathrm{~mm}$; that is, they became more acidic with increasing depth in the sediment until 5 to $9 \mathrm{~mm}$ depth, where the $\mathrm{pH}$ no longer decreased with increasing depth. The $\mathrm{pH}$ profiles we measured at the end of the experiment in cores from both the treatment and control areas had shapes similar to those from the control areas at the beginning of the experiment.

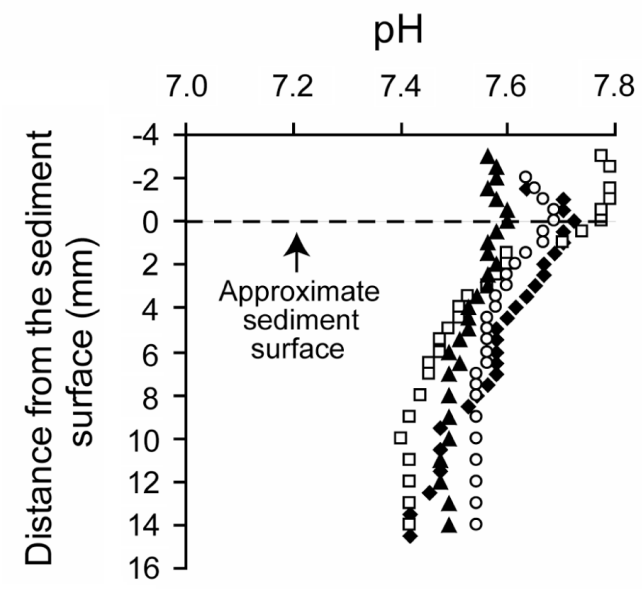

Fig. 6. $\mathrm{pH}$ profiles in 4 cores from the control area at the beginning of the experiment, showing background $\mathrm{pH}$ conditions for comparison with profiles in Fig. 5

\section{Traps}

\section{Abundance comparison}

The average abundance of harpacticoids (adults and copepodites) in traps from the treatment area $(=61.5)$ was significantly greater than that in traps from the control area $(=17.7)(p=0.011$, randomization test for 2-tailed difference between means, 4999 repetitions; Simon 1999) (Table 1). We chose randomization because it requires fewer assumptions than the more familiar, parametric tests.

\section{Internal controls}

At the end of the experiment, we recovered 13, 39, and 42 of the 50 individuals of the shallow-water species Schizopera knabeni that we had added to the traps in the control area and 15, 19, 23, and 39 individuals from traps in the treatment area. The means do not differ significantly $(p=0.41$, randomization test for 2-tailed difference between means, 4999 repetitions; Simon 1999), and the observed values overlap extensively.

Table 1. Numbers of harpacticoids collected in the traps ( 3 traps in the control, 4 in the treatment area). More were caught in the treatment than in the control area

\begin{tabular}{|lrrrrrrr|}
\hline & \multicolumn{3}{c}{ Control traps } & \multicolumn{4}{c|}{ Treatment traps } \\
\hline Adults & 15 & 6 & 21 & 42 & 33 & 45 & 47 \\
Copepodites & 3 & 5 & 3 & 19 & 15 & 34 & 11 \\
Total & 18 & 11 & 24 & 61 & 48 & 79 & 58 \\
\hline
\end{tabular}


Species-composition comparison

The multivariate test of similarity revealed that the species composition of the fauna in traps from the treatment area did not differ significantly from that in traps from the control area $(p=0.171)$.

\section{DISCUSSION}

\section{Exposure of traps inside the ring to carbon dioxide-rich seawater}

Our experiment was designed to create a treatment area, inside the ring of containers, where copepods were exposed to carbon dioxide-rich seawater. From previous experiments (see Barry et al. 2005) and from Brewer et al. (2005), we knew that the carbon dioxide in the containers would dissolve into the near-bottom water and react with the seawater carbonate system to produce carbon dioxide-rich seawater, which is denser than ordinary seawater and should flow along the seabed. Thistle et al. (2005) found that it also penetrated into the pore water.

The recording $\mathrm{pH}$ meters (Fig. 4) showed that the average $\mathrm{pH}$ of bottom waters inside the ring of containers during the experiment was mildly reduced $(-0.01 \mathrm{U})$, but with short episodes of moderate $\mathrm{pH}$ reduction $(-0.1$ to $-0.3 \mathrm{U})$. Bottom waters were transported by a sluggish mean flow that oscillated with the tides (J. P. Barry unpubl. data). Although no bottomwater measurements of $\mathrm{pH}$ were recorded at the control site, the $\mathrm{pH}$ at that location was unlikely to have been affected by the $\mathrm{pH}$ plume emanating from the treatment area, given the results from similar experiments (Barry et al. 2004).

In the cores taken from the control area at the beginning of the experiment, the $\mathrm{pH}$ at the sediment surface differed from that $10 \mathrm{~mm}$ below the surface (where it became more or less constant, Fig. 6) by $0.11,0.14,0.22$, and $0.37 \mathrm{pH}$ units. The $2 \mathrm{pH}$ profiles we measured with the in situ profiler close to the source of carbon dioxide (Fig. 5) contrasted with this pattern in that the profiles had minima in the upper $10 \mathrm{~mm}$, and the $\mathrm{pH}$ decreased from the sediment surface to the minima by 0.78 and $0.58 \mathrm{pH}$ units for Profiles 1 and 2, respectively. The $\mathrm{pH}$ of the upper $\sim 10 \mathrm{~mm}$ of the pore water at the profiler's location on Day 2 of the experiment was therefore much lower than would be expected from the profiles at the control site, indicating that the area adjacent to the containers had been exposed to acidic seawater. We assumed that these observations $\sim 2 \mathrm{~m}$ outside the ring of containers approximated conditions inside the ring.
Together, the results from the recording $\mathrm{pH}$ meter and the contrast in the profiles measured by the in situ profiler and those measured in cores from the control area at the beginning of the experiment suggest that we exposed the treatment area to carbon dioxide-rich seawater. At the end of the experiment, the $\mathrm{pH}$ profiles taken in the cores from the treatment area overlapped extensively with those from the control area (data not shown), suggesting that the carbon dioxide we deployed had dissipated.

\section{Harpacticoid behavior suggests that exposure to carbon dioxide-rich seawater is stressful}

The traps within the ring captured significantly more harpacticoid individuals than those from the control area. Our internal control (dead Schizopera knabeni adults) showed that the difference did not arise from a difference in the rate at which harpacticoids decayed to unrecognizability in the traps from the 2 areas. Rather, some harpacticoid individuals from the treatment area appear to have detected the advent of carbon dioxide-rich seawater and reacted by swimming away from the seabed, implying that exposure to carbon dioxide-rich seawater was stressful for them.

The composition of the fauna caught in the traps from the treatment area was indistinguishable from that of the fauna caught in traps from the control area. If this result is not a statistical artifact, it suggests that the species stimulated to enter the water were largely those that ordinarily use the near-bottom water and not those that do not, even though the latter were abundant in the treatment area. Deep-sea harpacticoids that normally venture into the near-bottom water therefore appear to have an avenue of at least temporary escape from advancing carbon dioxide-rich seawater.

In an earlier experiment, Thistle et al. (2006) found that $\sim 80 \%$ of harpacticoids that had been exposed to carbon dioxide-rich seawater died in place. They suggested that the carbon dioxide-rich seawater narcotized the harpacticoids and suppressed escape, a plausible scenario in that other investigators (see for example Tamburri et al. 2000 and Vetter \& Smith 2005) have found that carbon dioxide can narcotize deep-sea animals. Our results imply that at least some of the harpacticoid species in the deep sea can detect advancing carbon dioxide-rich seawater (directly or indirectly) and attempt to escape from it. The deep-sea fauna includes many species that live epibenthically and can swim (e.g. species of amphipods and isopods). Some deep-sea amphipods also appear to be able to detect carbon dioxide-rich seawater and swim away from it (Vetter \& Smith 2005), so one of the environmental consequences of localized carbon dioxide in- 
jection on or near the seafloor will be an attempt by at least some of the epibenthic fauna to emigrate. The success of such a strategy would depend on how far emerging species can disperse and how that distance compares to the area affected by elevated carbon dioxide concentrations.

One aspect of our experimental technique introduces an uncertainty into our conclusions. Because our goal was to collect individuals that left the sediment in response to advancing carbon dioxide-rich seawater, our traps were not sealed to the sediment and thus could collect both individuals residing beneath the traps and individuals transported beneath them. During the experiment, the 'Tiburon' was set on the seabed more often in the treatment area than in the control area. If harpacticoids left the seabed in response to this disturbance, more would have been in the near-bottom water in the treatment area than in the control area, which could have biased the catch of the traps. We were aware of this possibility and attempted to minimize it by giving collection of the traps priority during the recovery cruise. Also, our internal controls showed that some harpacticoid individuals decayed completely in the traps during the experiment. If disturbance by the vehicle during the first cruise caused the treatment-area traps to collect more individuals than the control-area traps, the former individuals, because they spent the most time in traps, would have been those most likely to have decayed completely before the traps were collected. This process would minimize their effect on our analyses.

Acknowledgements. L. Guidi-Guilvard shared preliminary data. D. Oliff built the emergence traps. The captain and crew of the RV 'Western Flyer', the 'Tiburon' team, K. Buck, L. Kuhnz, C. Lovera, T. Marshall, P. Walz, and P. Whaling aided in the field or laboratory. The manuscript was improved by the comments of E. Easton, A. B. Thistle, and 2 anonymous reviewers. The Department of Energy Office of Biological and Environmental Research supported this research under Award Numbers DE-FG02-05ER64070 and DE-FG0301ER63065, as did the US Department of Energy, Fossil Energy Group (Award DE-FC26-00NT40929). Significant support was also provided by the Monterey Bay Aquarium Research Institute (Project 200002). We are grateful for this kind help.

\section{LITERATURE CITED}

Armonies W (1988) Active emergence of meiofauna from an intertidal sediment. Mar Ecol Prog Ser 43:151-159

Barry JP, Seibel BA, Drazen JC, Tamburri MN and 8 others (2003) Deep-sea field experiments on the biological impacts of direct deep-sea $\mathrm{CO}_{2}$ injection. In: Proceedings of the Second Annual Conference on Carbon Sequestration. US Department of Energy, Alexandria, VA, p 1-7

Barry JP, Buck KR, Lovera C, Kuhnz L, Whaling PJ, Peltzer ET, Walz P, Brewer PG (2004) Effects of direct ocean $\mathrm{CO}_{2}$ injection on deep-sea meiofauna. J Oceanogr 60:759-766 Barry JP, Buck KR, Lovera C, Kuhnz L, Whaling PJ (2005) Utility of deep-sea $\mathrm{CO}_{2}$ release experiments in understanding the biology of a high $\mathrm{CO}_{2}$ ocean: effects of hypercapnia on deep-sea meiofauna. J Geophys Res 110: C09S12, doi:10.1029/2004JC002629

Bell SS, Walters K, Kern JC (1984) Meiofauna from seagrass habitats: a review and prospectus for future research. Estuaries 7:331-338

Bray JR, Curtis JT (1957) An ordination of the upland forest communities of southern Wisconsin. Ecol Monogr 27: 325-349

Brewer PG, Friederich G, Peltzer ET, Orr FM Jr (1999) Direct experiments on the ocean disposal of fossil fuel $\mathrm{CO}_{2}$. Science 284:943-945

Brewer PG, Peltzer ET, Walz P, Aya I and 6 others (2005) Deep ocean experiments with fossil fuel carbon dioxide: creation and sensing of a controlled plume at $4 \mathrm{~km}$ depth. J Mar Res 63:9-33

Carman KR, Thistle D, Fleeger JW, Barry JP (2004) Influence of introduced $\mathrm{CO}_{2}$ on deep-sea metazoan meiofauna. J Oceanogr 60:767-772

Clarke KR, Gorley RN (2001) Primer V.5: user manual/ tutorial. PRIMER-E, Plymouth

Fleeger JW, Carman KR, Weisenhorn PB, Sofranko H, Marshall T, Thistle D, Barry JP (2006) Simulated sequestration of anthropogenic carbon dioxide at a deep-sea site: effects on nematode abundance and biovolume. Deep-Sea Res I 53:1135-1147

Gedney N, Cox PM, Betts RA, Boucher O, Huntingford C, Stott PA (2006) Detection of a direct carbon dioxide effect in continental river runoff records. Nature 438:835-838

Hegerl GC, Bindoff NL (2005) Warming the world's oceans. Science 309:254-255

Hicks GRF (1986) Distribution and behaviour of meiofaunal copepods inside and outside seagrass beds. Mar Ecol Prog Ser 31:159-170

Hicks GRF, Coull BC (1983) The ecology of marine meiobenthic harpacticoid copepods. Oceanogr Mar Biol Annu Rev 21:67-175

Hoffert MI, Caldeira K, Benford G, Criswell DR and 14 others (2002) Advanced technology paths to global climate stability: energy for a greenhouse planet. Science 298: 981-987

Marchetti C (1977) On geoengineering and the $\mathrm{CO}_{2}$ problem. Clim Change 1:59-68

Noodt W (1971) Ecology of the Copepoda. Smithson Contrib Zool 76:97-102

Pörtner HO, Langenbuch M, Reipschlager A (2004) Biological impact of elevated ocean $\mathrm{CO}_{2}$ concentrations: lessons from animal physiology and Earth history. J Oceanogr 60: 705-718

Seibel BA, Walsh PJ (2001) Potential impacts of $\mathrm{CO}_{2}$ injection on deep-sea biota. Science 294:319-320

Seibel BA, Walsh PJ (2003) Biological impacts of deep-sea carbon dioxide injection inferred from indices of physiological performance. J Exp Biol 206:641-650

Seifried S (2004) The importance of a phylogenetic system for the study of deep-sea harpacticoid diversity. Zool Stud 43: 435-445

Shirayama Y (1995) Current status of deep-sea biology in relation to the $\mathrm{CO}_{2}$ disposal. In: Handa N, Ohsumi T (eds) Direct ocean disposal of carbon dioxide. Terra Scientific Publishing, Tokyo, p 253-264

Shirayama Y (1997) Biodiversity and biological impact of ocean disposal of carbon dioxide. Waste Manag 17:381-384

Simon JL (1999) Resampling: the new statistics, 2nd edn. 
Resampling Stats, Arlington, VA

Takeuchi K, Fujioka Y, Kawasaki Y, Shirayama Y (1997) Impacts of high concentrations of $\mathrm{CO}_{2}$ on marine organisms: a modification of $\mathrm{CO}_{2}$ ocean sequestration. Energy Convers Manag 38(Suppl):S337-S341

Tamburri MN, Peltzer ET, Friedrich GE, Aya I, Yamane K, Brewer PG (2000) A field study of the effects of $\mathrm{CO}_{2}$ ocean disposal on mobile deep-sea animals. Mar Chem 72:95-101

Thistle D (1978) Harpacticoid dispersion patterns: implications for deep-sea diversity maintenance. J Mar Res 36: 377-397

Thistle D (2003) Harpacticoid copepod emergence at a shelf site in summer and winter: implications for hydrodynamic

Editorial responsibility: Kenneth Heck (Contributing Editor), Dauphin Island, Alabama, USA and mating hypotheses. Mar Ecol Prog Ser 248:177-185

Thistle D, Carman KR, Sedlacek L, Brewer PG, Fleeger JW, Barry JP (2005) Deep-ocean, sediment-dwelling animals are sensitive to sequestered $\mathrm{CO}_{2}$. Mar Ecol Prog Ser 289: $1-4$

Thistle D, Sedlacek L, Carman KR, Fleeger JW, Brewer PG, Barry JP (2006) Simulated sequestration of industrial carbon dioxide at a deep-sea site: effects on species of harpacticoid copepods. J Exp Mar Biol Ecol 330:151-158

Vetter E, Smith CR (2005) Insights into the ecological effects of deep ocean $\mathrm{CO}_{2}$ enrichment: the impact of natural $\mathrm{CO}_{2}$ venting at Loihi seamount on deep sea scavengers. J Geophys Res 110:C09S13, doi:10.1029/2004JC002617

Submitted: March 3, 2006; Accepted: September 13, 2006 Proofs received from author(s): June 4, 2007 